\title{
Mixed Methods and Action Research: similar or different?
}

\begin{abstract}
This article attempts to analyse and compare ELT studies grounded solely in mixed methods and ELT action research studies based on a mixed methods approach in order to identify to what degree action research studies combining different methods in a single study comply with the principles of rigorous mixed methods study.
\end{abstract}

KEYWORDS: mixed methods, action research, ELT

\section{INTRODUCTION}

The hot debates carried on in the past over the superiority and application of two research traditions, quantitative and qualitative, highlighting their distinct ontological and epistemological foundations and dissimilar principles of research conduct, have resulted in the increasing interest in the third research orientation - mixed methods - which integrates the two above-mentioned approaches. The mixing of different research methods in a single study, however, already has quite a long tradition; it has been used in social sciences throughout the whole $20^{\text {th }}$ century. Since then abundant literature on mixed methods has been published, especially within social sciences, education and health care, and a new interdisciplinary Journal of Mixed Methods Research was founded in 2007.

The combining of research methods has also been employed in another research tradition, in action research studies. Action research has been ap- 
plied in a variety of academic areas, hence the profusion of approaches to defining what action research actually is. The analysis presented in this article focuses on research carried out for ELT studies, therefore we will limit our understanding of action research to classroom action research, which involves collecting and analysing classroom data by teachers, sometimes in cooperation with academics, in order to evaluate and improve teaching practice (Kemmis and McTaggart 2005). Theoretically, action research is usually situated within the qualitative tradition, yet the review of action research reports reveals the use of both qualitative and quantitative approaches, either separately or combined in one study, by which it may seem to be similar to mixed methods research (Creswell 2005). In this article an attempt is made to analyse and compare ELT studies using purely mixed methods and ELT action research studies based on mixing methods in order to find out whether action research studies combining qualitative and quantitative approaches are similar to or different from mixed methods research.

\section{MIXED METHODS RESEARCH}

Mixed methods research involves combining in a single study techniques, methods, approaches and language of both quantitative and qualitative traditions (Johnson and Onwuegbuzie 2004). Although such an approach may be criticised for mixing approaches rooted in distinct philosophical assumptions, it has been warranted by the view that the use of research methods is justified not by theoretical assumptions but by the final effect, the results (Johnson and Onwuegbuzie 2004), and, above all, by the research questions which dictate the choice of such methods which will guarantee obtaining the answers to those questions (Tasshakori and Teddlie 1998, Onwuegbuzie and Leech 2006).

Mixed methods research follows the usual research procedures which are, however, supplemented by some additional stages, such as: decision making and justification of method mixing, stating the aim of method mixing, choosing the means of method mixing and finally, interpretation of the combined results (Johnson and Onwuegbuzie 2004, Collins et al. 2006).

The comparison of mixed methods studies and action research studies presented later in the article will be based on these distinguishing features of mixed methods, as such they deserve further attention and will be discussed below in more detail. 


\subsection{Justification and goals in mixing quantitative and qualitative approaches in one study}

A review of the literature allows us to identify a variety of reasons why quantitative and qualitative approaches to research should be combined in a single study. The most important ones are the following:

(a) triangulation, that is investigating the issue from different positions and then converging the results (Cresswell 1999);

(b) the fundamental principle of mixed research, which says that the strengths of one method may overcome the weaknesses of another method if they are both applied in one study (Johnson and Turner 2003, Gelo et al. 2008);

(c) complementarity of data: qualitative data are used to illuminate numbers, and quantitative data add more precision to data presented in words or pictures (Greene et al. 1989, Johnson and Onwuegbuzie 2004);

(d) mixed methods research allows for investigating more complex problems from different perspectives, asking more questions, finding more complex answers (Greene et al. 1989, Johnson and Onwuegbuzie 2004, Gelo et al. 2008);

(e) the results of one method may provide an impetus for designing a further step in the research with the use of another method, or may trigger questions for another method study (Greene et al. 1989);

(f) mixed methods study allows reaching a larger audience (Dörney 2007);

(g) the research claims become stronger if the data come from a variety of methods, the results may be more persuasive and convincing for policy-makers, and it ensures "less waste of potentially useful information" (Gorard and Tylor 2004);

(h) mixed methods research allows for a presentation of more divergant views, it allows to simultanously answer exploratory and confirmatory questions (Schulenberg 2007);

(i) some research questions can be answered only by combining the two approaches within one study (Bryman 2006).

\subsection{Types of research questions}

Research questions in mixed methods are extremely important since they are believed to lead and determine the whole research process, the methods used, research design, the sample and the sampling, data collection tools and data analysis (Morse et al. 2003, Johnson and Onwuegbuzie 2004, Bryman 2006, Onwuegbuzie and Leech 2006). In Onwuegbuzie and Leech's (2006) 
view, a mixed methods question includes both a quantitative research question and a qualitative research question whereas Cresswell (1999) does not see the necessity to combine both types in one question; it is essential, however, to pose both quantitative and qualitative questions for one study, which means that mixed research requires at least two questions, one quantitative and one qualitative (Teddlie and Tashakkori 2009). Different types of research designs will be characterized by different sets and types of questions.

\subsection{Sampling}

Quantitative and qualitative methods differ in the size of samples studied as well as in the sampling techniques. The sampling in mixed methods study needs sampling that is a combination of characteristics typical of qualitative and quantitative sampling, and each of the types is used for either the quantitative or qualitative phase of the research. The size of samples used in one study may differ from large groups to a small number of units. The decisions concerning sampling are made before the study starts, however, for qualitative phases decisions may be taken in the course of the study (Tashakkori and Teddlie 2003). The most frequently applied sampling strategies are: basic mixed methods sampling, sequential mixed methods sampling, and parallel mixed methods sampling.

\subsection{Data collection methods}

In mixed methods research data collection involves mixing quantitative and qualitative approaches to data collection. The mixing can take place at the intermethod or intramethod level. Intramethod mixing (data triangulation) involves concurrent or sequential mixing of qualitative and quantitative components within a single method and intermethod mixing (method triangulation) employs concurrent or sequential mixing of two or more methods (Johnson and Turner 2003). The methods for data collection mostly used in mixed methods research are: questionnaires, interviews, focus groups, tests, observation, secondary data (personal and official documents, physical data, archived research data). They are used either in their pure form or in a mixed form.

\subsection{Means of implementation of research procedures}

The mixing of qualitative and quantitative methods may occur at different levels or components of a study: the research objective, question formulation (conceptualization stage), type of data and procedures (experiential or 
methodological/analytical stage), type of analysis and type of interference (inferential stage) (Tashakkori and Teddlie 2003, Onwuegbuzie and Leech 2006). The mixing may be either full or partial. Fully mixed methods involve mixing within one or more stages of the research process or across stages, whereas in partially mixed designs the qualitative and quantitative elements operate separately and they are mixed only at the interpretation stage. Qualitative and quantitative methods are applied either concurrently or sequentially. Additionally, the status of each method may differ (dominant status) or be the same (equal status) (Onwuegbuzie and Leech 2006).

Depending on the research questions and data collection methods used, the appropriate data analysis methods need to be applied. Tashakkori and Teddlie (2003) identified six different types of data analysis. The first one involves parallel analysis of qualitative and quantitative data. Sequential analysis involves analysing first the qualitative data and then the quantitative or vice versa. In mixed methods analysis qualitative data may be converted for quantitative analysis or quantitative data may be qualitatized. Inherently, mixed data analysis means that researchers plan in advance to use the same set of data to generate both qualitative and quantitative information. It is also possible to apply multilevel data analysis, where different techniques are used at different levels to answer interrelated questions. Fully integrated mixed data analysis involves analysing data in an interactive manner at all stages of research.

\section{COMPARISON OF MIXED METHODS RESEARCH AND ACTION RESEARCH REPORTED IN ELT RESEARCH ARTICLES}

The main goal of this comparison is to identify to what extent these two approaches to research, mixed methods and action research based on mixed methods, are similar or different.

The research articles chosen for the study all come from the English Language Teaching field. The criteria for the choice of articles have been: the source of the article (academic journal), field (English as a foreign/second language), explicit reference to the application of mixed methods in one case and action research in the second case, and finally an article should include a separate research methods section in discussing the method used. The last criterion was important since it gave a common ground for comparison, although it reduced the number of action research articles suitable for the analysis. The chosen articles and their study topics are presented in table 1 and 2. 
Table 1. Mixed methods articles

\begin{tabular}{|l|l|l|}
\hline \multicolumn{1}{|c|}{ Author } & \multicolumn{1}{|c|}{ Source } & \multicolumn{1}{c|}{ Purpose of the study } \\
\hline $\begin{array}{l}\text { Amuzie, } \\
\text { Winke 2009 }\end{array}$ & System & $\begin{array}{l}\text { The effects of study abroad on } \\
\text { language learner beliefs about } \\
\text { learner autonomy (USA) }\end{array}$ \\
\hline Barkaoui 2007 & Assessing Writing & $\begin{array}{l}\text { The effects of different rating } \\
\text { scales on the rating of essays, } \\
\text { essay scores and raters percep- } \\
\text { tions (Tunisia) }\end{array}$ \\
\hline Chang 2007 & System & $\begin{array}{l}\text { The influence of group processes } \\
\text { on individual learner autonomy - } \\
\text { beliefs and behaviours (Taiwan) }\end{array}$ \\
\hline Chen 2008 & Teaching and Teacher Education & $\begin{array}{l}\text { Factors influencing teachers' use } \\
\text { of the Internet in EFL instruction } \\
\text { (Taiwan) }\end{array}$ \\
\hline Chiang 2008 & Teaching and Teacher Education & $\begin{array}{l}\text { The effects of integrating teacher } \\
\text { training courses with practical } \\
\text { experience (Taiwan) }\end{array}$ \\
\hline $\begin{array}{l}\text { Mazdayasna, } \\
\text { Tahririan 2008 }\end{array}$ & $\begin{array}{l}\text { Journal of English for Academic } \\
\text { Purposes }\end{array}$ & $\begin{array}{l}\text { ESP needs of students of medical } \\
\text { sciences (Iran) }\end{array}$ \\
\hline
\end{tabular}

Table 2. Action research articles

\begin{tabular}{|l|l|l|}
\hline \multicolumn{1}{|c|}{ Author } & \multicolumn{1}{|c|}{ Source } & \multicolumn{1}{c|}{ Purpose of the study } \\
\hline Hall Haley 2004 & Teachers College Record & $\begin{array}{l}\text { The effects of multpiple intelli- } \\
\text { gences on teaching foreign lan- } \\
\text { guages (USA) }\end{array}$ \\
\hline Mavor 2001 & Teaching in Higher Education & $\begin{array}{l}\text { Socio-cultural effects of teaching } \\
\text { English for Academic Specific } \\
\text { Purposes (Portugal) }\end{array}$ \\
\hline $\begin{array}{l}\text { Orsini-Jones, } \\
\text { Jones 2007 }\end{array}$ & $\begin{array}{l}\text { Arts \& Humanities in Higher } \\
\text { Education }\end{array}$ & $\begin{array}{l}\text { The effect of autonomy and VLE } \\
\text { on student motivation (UK) }\end{array}$ \\
\hline Rahimi 2009 & Reading and Writing & $\begin{array}{l}\text { The effect of feedback on writing } \\
\text { (Iran) }\end{array}$ \\
\hline $\begin{array}{l}\text { Soler Cervera et al. } \\
2005\end{array}$ & IBÉRICA & $\begin{array}{l}\text { An Internet course and its influ- } \\
\text { ence on students (Spain) }\end{array}$ \\
\hline $\begin{array}{l}\text { Vásquez, } \\
\text { Reppen 2007 }\end{array}$ & Language Awareness & $\begin{array}{l}\text { The role of post-observation stu- } \\
\text { dent-supervisor interaction (USA) }\end{array}$ \\
\hline
\end{tabular}

The focus of comparison between the studies in each set was on the components of mixed methods described in the previous section. 


\section{RESULTS}

\subsection{Justification for combining quantitative and qualitative approaches}

The most common reason for applying the mixed methods approach in both action research and mixed methods studies is the need for complementarity of data and triangulation. However, in action research studies only in two cases was the choice of mixing methods explicitly justified. For example, Rahimi (2009) believes that in his study of feedback in teaching writing it is useful to support quantitative data with qualitative data in order to obtain a richer insight into the issue.

The authors of mixed methods studies provide more elaborate justifications for their choice of this research approach in each case but one. Usually in the Methods section the reader is informed about the research methods used and the purposes of the application of each of the data collection tools are presented. Exceptionally, in Barkaoui's study (2007) the explicit reference to the mixed methods approach is made only in the title and in the abstract. Later in the text this study is contrasted with others based on either solely quantitative or qualitative measures and it is emphasized that by combining the two methods in one study the investigated problem of the effects of different rating scales on L2 essay scores, rating processes and raters' attitudes can be better understood. Similarly, Amuzie and Winke (2009), in their study of the effects of study abroad on language learner beliefs concerning learner autonomy, believe that the combination of qualitative and quantitative methods is suitable for investigating such a complex phenomenon as changes in learner beliefs. They also refer back to the research tradition in social science and SLA which has confirmed the usefulness of mixed methods, especially when the approach is used for triangulation purposes. Consequently, they used qualitative data from interviews to illustrate the reasons for changes in beliefs, but the questions for the interview were based on the results of a quantitative instrument, a belief questionnaire.

\subsection{Types of research questions asked in each study}

The studies of Mazdayasna, Tahririan (2008) and Chiang (2008) include 4 research questions each, the remaining studies pose 3 questions each. In Chiang's study two of the questions seek quantitative data, and two need qualitative data to be answered. In the case of Mazdayasna and Tahririan's 
study (2008) all the questions begin with "What" and, depending on the approach, the answers to these questions can be pursued either quantitatively or qualitatively. What the authors actually did was approach each question first with a qualitative tool (interview), and then, on the basis of the interview results, prepare a quantitative tool (questionnaire). In Chang's (2007), Barkaoui's (2007) and Amuzie and Winke's (2009) studies 2 quantitative questions were followed by a single qualitative one, in Chen's (2008) study the situation was reversed, one quantitative question was followed by two qualitative ones. The qualitative questions usually asked about teacher/learner perceptions, the reasons behind certain situations and the factors involved. The quantitative questions asked about the effects of interventions, the kind and extent of the phenomena, and statistical correlations.

Contrary to mixed methods studies, in action research studies only in two cases (Rahimi 2009, Hall Haley 2004) are research questions posed explicitly. In the remaining studies the authors state the problem or define the goal of the research. Mavor (2001), for example, describes problems involved in the encounter between two cultures: the students' Portuguese culture and the teacher's English culture, and the adjustment of both. Similarly, OrsiniJones and Jones (2007) do not pose any questions, instead a problem and research aim are stated, namely the students' learning experience with a grammar project is the focus of the evaluation.

\subsection{Population studied}

The analysis of population studied reveals a variety in the samples. It is quite surprising that in Chiang's (2008) study the sample for the quantitative and qualitative studies is the same and involves only 13 student-teachers. This number is appropriate for a qualitative study, however it is below the numbers expected for quantitative research. In the remaining studies the population investigated in the quantitative part is much bigger than the population needed for the qualitative part. For example, Chang (2007) has chosen for his study four groups of students comprising 152 participants in total. Subsequently, after the quantitative phase has been completed, he introduces 12 interviewees for the qualitative phase, chosen from the entire group. Similarly, Chen (2008) and Amuzie and Winke (2009) in their quantitative stage surveyed 311 EFL teachers and 70 students respectively, and in the subsequent qualitative phase, interviewed 22 teachers and 14 students, respectively. The largest group participated in Mazdayasna and Tahririan's study (2008) and involved 681 students, 168 subject instructors, and 6 English instructors to complete a questionnaire and 92 students and 40 subject instructors to participate in interviews. 
The samples of participants in action research studies are much smaller. Mavor (2001), for example, administered questionnares to a group of 16 learners only. Then two classes were observed with 15 and 10 students respectively and surveyed and four teachers were observed. Rahimi (2009) studied 56 Iranian students of English, divided into two groups, an experimental and a control one. The study by Hall Haley (2004) in this group is exceptional in terms of population since it involved 23 teachers who investigated as many as 650 learners.

\subsection{Data collection methods used in the studies}

The data in mixed methods studies come from questionnaires of different types and from interviews with research participants. In addition, a selfreport questionnaire, reflective logs/essays and think aloud protocols and documents have been used. The questionnaires provided mainly quantitative data, the remaining tools were appriopriate for gathering qualitative data. In Amuzie and Winke's (2009) study, interviews were based on the results of a questionnaire, in Mazdayasna and Tahririan's study (2008), on the contrary, a questionnaire was prepared on the basis of an earlier interview.

Action research studies employed a greater variety of data collection tools. For example, Mavor (2001) mentions non-participant observation, video-recordings, post-observation semi-structured interviews, questionnaires. Quantitative data in Rahimi's (2009) research came from test scores and essay scores analysed statistically. Qualitative data were collected in interviews for the purpose of triangulation and further support of the quantitative data. Observation and post-observation meetings which were audiorecorded in Vasquez and Reppen's study (2007) were used to obtain both quantitative and qualitative data; the quantitative data were analysed first and then they were supplemented with the analysis of qualitative data. A variety of data collection tools was also used by Hall Haley (2004): lesson plans, daily logs, weekly journals, observation, informal interviews, exit slips, surveys, learner grades.

\subsection{The implementation of research procedures}

In mixed methods studies data collection was usually sequential, meaning that first one tool was used and then another. For example, the combination of quantitative survey and qualitative interview was employed in 
Chang's (2007) study of the correlation of learner beliefs and group processes. In this study the interviews were conducted a few months after the survey data had been analysed statistically. This was essential to select the interviewees and prepare relevant questions for the interview. The results were presented and discussed in separate sections. Chen's (2008) study of teachers' internet use is an example of concurrent use of data collection tools. The survey aimed at collecting quantitative data which later on were analysed statistically. Concurrently the interviews were performed, however the interview protocol had been developed earlier taking into account the initial responses to the survey. The data yielded by the interview responses were analysed within a phenomenological framework and coded into emerging categories. The results from both tools were compared, synthesized and presented in separate sections. Then they were integrated in the discussion section.

There are two studies which employed both concurrent and sequential data collection. Chiang (2008), for example, at the beginning of his study, employed a survey with closed and open-ended items thereby mixing the two approaches in one tool. Simultaneously a Teacher Efficacy Scale pre-test was administered. Quantitative and qualitative data were also collected at the end of the study. The Teacher Efficacy Scale post-test was applied after the participants wrote their reflective essays on their expectations and observations before and after the course. Earlier, an interview seeking a description of teacher perceptions of a practically integrated TEFL methods course was conducted. During the course, concurrently to other data collection procedures, the teachers were asked to keep a reflective log. Quantitative data were analysed first using statistical methods. The analysis of the qualitative data was performed by content analysis, taking as a starting point the quantitative outcome. Categories and subcategories were identified. Recurring themes and patterns were identified by comparisons with the quantitative data. In this integrative analysis the quantitative results constituted a context for qualitative data. The integrated results were presented in a single section.

In the mixed methods studies examined, quantitative data were analysed statistically and qualitative data were submitted to coding for recurring themes. In Barkaoui's (2007) study, qualitative data were also analysed statistically. The qualitative and quantitative results were presented separately, apart from in Chiang's (2008) study, where the results were integrated in the summing up, discussion and conclusion sections.

In action research studies only in two cases are as few as two data collection tools mentioned, in one study there are 7 tools employed, the remaining ones all report three tools. In all the action research studies the data from 
different sources were combined throughout the whole study. Data collection tools were applied sequentially (e.g. Rahimi 2009) and concurrently (e.g. Soler 2005). Also both sequential and concurrent data collection was possible. Mavor (2001) first used observations and video-recordings for qualitative and quantitative data, and then interviews with teachers and questionnaires (qualitative and quantitative data) and interviews with students. In these studies quantitative data were not statistically analysed, only simple calculations were performed and the results were presented in graphs. Qualitative data were illustrated with citations from the interviews and questionnaires.

\section{CONCLUSIONS}

In this article we have examined how the combining of research methods is performed in mixed methods studies and in action research studies. The comparison of these two research approaches, although it focused only on some aspects due to space limits, allows us to identify similarities and differences between them.

The choice of a particular research method may be conditioned either by the researcher's paradigm preferences or research questions. In the studies examined there were no references to any of the epistemological, axiological or methodological assumptions which guided combining the methods. However, mixed methods studies include justifications for combining qualitative and quantitative methods, whereas action research studies do not provide the reader with such information. The analysis reveals that the goals of combining the methods are similar in both types of studies: triangulation and data complementarity. The combining of methods takes place at different stages: asking questions, data collection, data analysis. Questions are posed in all mixed methods whereas in the case of action research, questions are posed only in two studies, the remaining ones are guided by a goal pursued by the researcher. In mixed methods large populations are usually studied, while smaller populations are set apart for qualitative investigation. In action research smaller populations are investigated and they remain the same for both the quantitative and qualitative part of the research. The most popular data collection tools in all of these studies are questionnaires and interviews which are supplemented by other tools, such as think aloud protocols and reflective essays (in mixed methods) and observation, field notes, documents, journals and discussions (in action research). Action research studies usually employ a larger variety of data collection tools. In mixed methods research sequential data collection dominates, whereas in action 
research the sequential-concurrent model is dominant. The qualitative and quantitative data collected in mixed methods research are analysed separately, statistically and qualitatively, and integrated in the discussion and conclusion sections. In action research quantitative data are simply calculated and discussed together with the qualitative data, but the process of analysis is not described.

To sum up the comparison of these two research approaches it can be stated that:

a) Combining qualitative and quantitative approaches in research is a basic principle in mixed methods approach, but only some action research studies employ such combinations.

b) The two research methods are similar in stating the goals for mixing methods and in data collection.

c) The two research methods may differ in the way qualitative and quantitative approaches are combined, in data analysis and data presentation.

d) They are different in the way the research is written up.

The comparison of these two sample sets of mixed methods research and action research studies reveals that these are two distinct research methods. A mixed methods approach requires firm knowledge of mixed methods principles from the researcher, of both qualitative and quantitative research procedures and the skills necessary to perform them, including the ability to perform statistical operations. It also requires the ability to write up such a research project. The action research procedure is also very demanding of the researcher, who is expected to follow a cyclical research process in pursuing his or her goal but, on the other hand, can be more flexible in his or her choice of approach to the research (qualitative, quantitative or both). This makes action research more easily available for teacher researchers who may not be trained in conducting research using statistical methods. On the other hand, if action research claims to be based on mixed methods, it should abide by the rigours of this method.

\section{REFERENCES}

Bryman, A., 2006. Paradigm Peace and the Implications for Quality. In: International Journal of Social Research Methodology 9/2, 111-126.

Collins, K.M.T., Onwuegbuzie, A.J., Sutton, I.L., 2006. A Model Incorporating the Rationale and Purpose for Conducting Mixed-Methods Research in Special Education and Beyond. In: Learning Disabilities: A Contemporary Journal 4 (1), 67-100.

Creswell, J.W., 1999. Mixed-Method research: Introduction and Application. In: Cizek, G.J. (ed.), Handbook of Educational Policy, 455-472. San Diego, USA: Academic Press. 
Creswell, J.W., 2005. Educational research: Planning, conducting, and evaluating quantitative and qualitative research. Upper Saddle River, NJ: Pearson Education.

Dörnyei, Z., 2007. Research Methods in Applied Linguistics. Oxford: Oxford University Press.

Gelo, O., Braakman, D., Benetka, G., 2008. Quantitative and Qualitative Research: Beyond the Debate. In: Integrative Psychological Behavior 42, 266-290.

Gorard, S., Taylor, Ch., 2004. Combining Methods in Educational Research. Maidenhead, England: Open University Press.

Greene, J.C., Caracelli, V.J., Graham, W.F., 1989. Toward a conceptual framework for mixedmethod evaluation designs. In: Educational Evaluation and Policy Analysis 11/3, 255-274.

Johnson, R.B., Turner, L.A., 2003. Data collection strategies in mixed method research. In: Tashakkori A., Teddlie, C. (Eds.). Handbook of mixed methods in social and behavioral research, Thousand Oaks: Sage, 297-319.

Johnson, R.B., Onwuegbuzie, A.J., 2004. Mixed Methods Research: A Research Paradigm Whose Time Has Come. In: Educational Researcher, 33/7, 14-26.

Kemmis, S., McTaggart, R., 2005. Participatory action research: Communicative action and the public sphere. In: Denzin, N., Lincoln, Y. (Eds.) Handbook of Qualitative Research. Beverley Hills, CA: Sage, 559-603.

Morse, J.J., Niehaus, L., Wolfe, R.R., Wilkins, S. 2003. The role of theoretical drive in maintaining validity in mixed-method research. In: Qualitative Research in Psychology 3, 279-291.

Onwuegbuzie, A.J., Leech, N.L., 2006. Linking Research Questions to Mixed Methods Data Analysis Procedures. In: The Qualitative Report, 11/3. 474-498.

Schulenberg, J.L. 2007. Analysing Police Decision-Making: Assessing the Application of a Mixed-Method/Mixed-Model Research Design. In: International Journal of Social Research Methodology, 10/2, 99-119.

Tashakkori, A., Teddlie, C., 1998. Mixed Methodology: Combining qualitative and quantitative approaches. Thousand Oaks, CA: Sage.

Tashakkori, A., Teddlie, C. 2003. The past and future of mixed methods research: From data triangulation to to mixed model designs. In: Tashakkori, A., Teddlie, C. (Eds.). Handbook of mixed methods in social and behavioral research, Thousand Oaks: Sage, 671-702.

Teddlie, C., Tashakkori, A. 2009. Foundations of Mixed Methods Research. Thousand Oaks: Sage.

\section{ANALYSED ARTICLES}

Amuzie, G.L., Winke, P., 2009. Changes in language learning beliefs as a result of study abroad. In: System 37/3, 366-370.

Barkaoui, K., 2007. Rating scale impact on EFL essay marking: A mixed-method study. In: Assessing Writing 12, 86-107.

Chang, L.Y., 2008. The influences of group processes on learners' autonomous beliefs and behaviors. In: System 35/3, 322-337.

Chen, Y.L., 2008. A mixed-method study of EFL teachers' Internet use in language instruction. In: Teaching and Teacher Education 24, 1015-1028.

Chiang, M.H. 2008. Effects of fieldwork experience on empowering prospective foreign language teachers. In: Teaching and Teacher Education 24/5, 1270-1287.

Hall Haley, M. 2004. Learner-Centered Instruction and the Theory of Multiple Intelligences With Second Language Learners. In: Teachers College Record 106/1, 163-180.

Mavor, S., 2001. Socio-culturally Appropriate Methodologies for Teaching and Learning in a Portuguese University. In: Teaching in Higher Education 6/2, 183-201. 
Mazdayasna, G., Tahririan, T.H., 2008. Developing a profile of the ESP needs of Iranian students: The case of students of nursering and midwifery. In: Journal of English for Academic Purposes 7, 277-289.

Orsini-Jones, M., Jones, D., 2007. Supporting Collaborative Grammar Learning via a Virtual Learning Environment. In: Arts \& Humanities in Higher Education 6/1, 90-106.

Rahimi, M., 2009. The role of teacher's corrective feedback in improving EFL Iranian learners' writing accuracy over time: is learner's mother tongue relevant? In: Reading \& Writing $22 / 2$.

Soler, A., Rueda, R., Arnó, E., 2005. Students' profile as autonomous learners in an Internetbased EAP course. In: IBERICA 9, 53-78.

Vásquez, V., Reppen, R., 2007. Transforming Practice: Changing Patterns of Interaction in PostObservation Meetings. In: Language Awareness 16/3, 153-172. 